\title{
A transiência dos modelos econômicos: performatividade e econometria*
}

\author{
The Transience of Economic Models: Performativity and Econometrics
}

\author{
Rafael Galvão de Almeida**
}

\begin{abstract}
Resumo: Esse artigo tem como objetivo resenhar a literatura sobre a performatividade da economia, analisando suas origens na filosofia da linguagem de John L. Austin, até suas aplicações por Michel Callon e Donald MacKenzie. Partindo dessa análise, o artigo disserta sobre os canais de influência que a econometria pode influenciar o sistema econômico (economy) e como pode se tornar um instrumento de política performativa. $\mathrm{O}$ artigo conclui que é difícil de determinar efeitos performativos claros da econometria na economia e reflete sobre a transiência dos modelos.
\end{abstract}

Palavras-chave: Performatividade; Econometria; Modelos econômicos

\begin{abstract}
This article has as its objective to review the literature on performativity of economics, analyzing its origins in J. L. Austin's philosophy of language, and its applications by Michel Callon and Donald MacKenzie. From this analysis, the article writes about the influence channels through which econometrics and influence the economy, and how it can become an instrument of performative policy. The article concludes that it is difficult to determine clear performative effects of econometrics in the economy, and it reflects on the transience of models.
\end{abstract}

Keywords: Performativity; Econometrics; Economic models

JEL: B23, B41, Z13

\footnotetext{
* Submissão: 26/07/2019 | Aprovação: 05/07/2020 | DOI: 10.5380/re.v42i78.68165

*** Doutor em economia (CEDEPLAR/UFMG), Brasil. |E-mail: rga1605@ gmail.com | ORCID: 0000-00023582-9906
} 
Quando modelos produzem resultados que variam muito, eles

recebem atenção baseada nas posições dos seus autores, suas implicações políticas, ou sua capacidade de propagação, não por causa de seus pressupostos - Elizabeth Popp Berman ${ }^{1}$

\section{Introdução}

A ciência, incluindo a ciência econômica, é um eterno produto inacabado. É inacabado porque ela está sempre evoluindo na sua tentativa de organizar e tomar proveito do conhecimento que adquirimos de um mundo aparentemente caótico. Por essa razão, economistas devem trabalhar para desenvolver modelos melhores. Mas como funciona esse processo de substituição de modelos antigos por novos?

Na filosofia da ciência, o estudo clássico de Kuhn (1970 [1962]) argumenta que podem haver mudanças súbitas - revoluções - durante a mudança de paradigma científico. O exemplo mais claro fora da economia é o modelo ptolemaico heliocêntrico. Ele reinou por séculos como o modelo científico padrão do período medieval, até ser desafiado e abandonado graças ao progresso da ciência, na forma do modelo newtoniano. C. S. Lewis escreveu sobre esse modelo: "poucas construções da imaginação combinam esplendor, sobriedade e coerência no mesmo nível” (Lewis, 2015 [1964], p. 205). Essas características, no entanto, não foram suficientes para manter o status de dominância do modelo diante de novas alternativas.

Em economia, não é diferente. Basta folhear as páginas de um manual de história do pensamento econômico para ver como modelos outrora importantes, como o Tableau Económique e o modelo de ganhos de comércio original de Ricardo, foram superados e se tornaram parte da história da economia. Assume-se que suas contribuições são indiretamente incorporadas ao estado atual da fronteira da disciplina (Arida, 1984, p. 16).

Outra característica dos modelos econômicos é que muitos deles têm como objetivo realizar um impacto na sociedade. Todo economista deseja reconhecimento acadêmico, através de leitura de suas pesquisas e escritos. Porém, poucos são os trabalhos que conseguem ultrapassar as fronteiras da academia e um número ainda menor deles despertam instantaneamente o interesse dos legisladores públicos a ponto de orientá-los na tomada de decisão. E, se o economista chegou a esse ponto, ele só fez seu trabalho. A economia tradicional considera que os economistas agem

\footnotetext{
${ }^{1}$ Palestra "The Politics of Economics in the time of COVID-19 \#1 Valuing Life", 5 de maio de 2020.
} 
como descritores da realidade; sua função é descobrir "conjuntos de leis e fatos econômicos [...] e o que fazer com isso é deixado a políticos e eleitores" (Dupré, 2007 , p. 35) - a menos que os economistas escolham participar de forma mais ativa, como legisladores, por exemplo.

Assim, a descrição da realidade é uma função importante dos modelos. Porém, é possível que a teoria econômica vá além de mera descrição? Faulhaber e Baumol (1988) fazem um survey sobre o efeito que os "produtos da academia" teriam no mundo real. Isto é, as inovações técnicas dos economistas, criadas para descrever a realidade, que renderam aplicações visíveis ${ }^{2}$. Eles argumentam que uma boa parte dessas inovações teve efeitos não esperados. Economistas não seriam apenas 'descritores' mas também 'inventores': “a evidência é suficientemente forte para justificar considerações sérias sobre a contribuição do nosso conhecimento teórico não apenas no nosso entendimento, mas também sobre o objeto de nosso estudo: a operação da economia" (p. 597).

Existe a possibilidade de não só a ciência econômica ter uma função descritiva de seu objeto de estudo, a economia, mas também de ter alguma influência no seu objeto? George Stigler (1982, p. 61) argumenta que essa transposição não é possível pois "os problemas da vida econômica" não mudam de forma frequente e radical. Porém, Faulhaber e Baumol relataram que um dos principais obstáculos à publicação do seu artigo foi a insinuação de que, devido a esse poder dos economistas, a teoria econômica não é livre de julgamentos de valor (value-free) - o que torna a substituição de modelos antigos por novos mais complicada do que se supõe.

Novamente, Stigler acreditava que "os economistas exercem uma influência menor e pouco detectável nas sociedades que vivem" (Stigler, 1975, p. 351 apud Blinder, 1999, p. 255³). Em contraste, Alan Blinder escreve "eu não acredito que isso seja mais verdade".

Desde que [Stigler] escreveu essas palavras, as economias do mundo real, incluindo a nossa, mudaram de várias maneiras que as tornam mais alinhadas com os modelos pristinos imaginados pela teoria econômica. Em um sentido curioso, a vida veio a imitar a arte (Blinder, 1999, $\mathrm{p}$. 255, ênfase adicionada).

\footnotetext{
${ }^{2}$ Os seguintes "produtos" de economistas foram analisados: análise marginal, valor presente descontado, tarifação horo-sazonal, previsão econométrica, modelo de seleção de portfólio, coeficiente beta e análise de duration, modelo de Black-Scholes de preço ótimo de opção, tarifação de Ramsey, e o stand-alone cost test.

${ }^{3}$ STIGLER, G. Do economists matter? Southern Economic Journal, v. 42, n. 3, p. 347-354, 1976.
} 
A experiência de Blinder como um economista público americano lhe deu uma visão política importante de como os agentes econômicos agem e como o poder público reage a mudanças na teoria econômica. Na prática, economistas têm um papel importante como "missionários": "economistas que entram em contato direto com decisões do governo descobrem que eles não podem limitar seu papel a técnicos neutros" (Nelson, 1987, p. 50)4.

Para considerar essa possibilidade, a tese de performatividade é um meio de analisar a relação entre a economia como disciplina (economics) e a economia como objeto (economy), pois ela borra essa separação entre sujeito e objeto (Ottoni, 2002, p. 126). A performatividade está associada às ciências humanas, nos campos de linguística, estudos sociais e de gênero, filosofia analítica e sociologia econômica (Cavanaugh, 2015). Devido ao seu efeito potencial na economia, economistas têm se interessado pelo tema (Boldyrev; Svetlova, 2016; Brisset, 2019). Os estudos mais relevantes aos economistas vêm da performatividade no mercado financeiro (Mackenzie, 2006) e no mercado de morangos de Fontaines-en-sologne (GarciaParpet, 2003 [1986]).

Economistas, especialmente no ramo da macroeconomia, tendem a usar a metáfora kuhniana da revolução para descrever o avanço na disciplina, especialmente a revolução keynesiana na década de 1930 e a revolução de expectativas racionais na década de 1970 (De Vroey, 2016, p. 379). A revolução da década de 1970 é a que nos interessa. Antes dela, assim como o modelo ptolemaico em seu tempo, modelos macroeconométricos dominaram a paisagem macroeconômica do período após a Segunda Guerra Mundial até a revolução de expectativas racionais.

Durante esse período, a econometria foi confirmada como uma das mais importantes disciplinas da economia, porque, para o ponto de vista ortodoxo, não há melhor forma de desenvolver explicações e confrontar os modelos com a realidade, com uma abordagem quantitativa robusta (Pinto, 2011, p. 436). Modelos

\footnotetext{
${ }^{4}$ Kogut e Macpherson (2012) argumentaram que a influência dos economistas treinados em universidades americanas, onde o liberalismo estava em voga durante a década de 1980, causou um efeito significante na adoção de políticas de privatização e de tornar o Banco Central mais independente. Mesmo que "pareça cínico, incrível ou ambos" (p. 1319) existe evidência de que a comunidade econômica possibilitou a difusão de certas ideias econômicas.

5 O mercado de morangos de Fontaines-en-sologne foi um exemplo de um mercado que conseguiu reproduzir o modelo de equilíbrio geral de forma quase perfeita, graças ao esforço de um advogado cujo único conhecimento de economia foi uma disciplina de introdução à economia feita em seu mestrado. Ver Garcia-Parpet (2003 [1986]) para mais informações.
} 
enormes, de até mais de 400 equações, eram desenvolvidos para achar relações de correlação e causalidade, a fim de providenciar informações de planejamento estratégico e contribuir para o processo de desenvolvimento (Welfe, 2013).

Porém, toda essa estrutura recebeu críticas decisivas por meio do teorema da impossibilidade de Arrow, a crítica de Lucas, e críticas diversas de economia política (Acoccella et al., 2016, p. 7). Após essas mudanças, as expectativas racionais se tornaram o paradigma macroeconômico (Hoover, 1992; De Vroy, 2016) e facilitaram a adoção de modelos de calibragem, que abririam caminho para os modelos de equilíbrio geral dinâmico estocástico, ou DSGEs (Tovar, 2009). Esses modelos, que influenciaram uma geração, caíram perante novos dados e modelos e revoluções de paradigma.

Tendo isso em mente, este artigo tem quatro seções, contando essa introdução. A segunda seção detalha o que é performatividade e como ela pode ser aplicada à economia; a terceira seção analisa como os canais de influência propostos por Dequech (2018) podem indicar como a econometria penetrou a economia; a quarta seção disserta sobre a mudança dos modelos macroeconométricos na década de 1970, e de como sua influência se propagou; a quinta seção conclui ao afirmar que a performatividade deve ser direcionada a estudos de caso e pode auxiliar a compreender a relação entre teoria e prática e o caráter transiente dos modelos.

\section{Performatividade: da linguística à economia}

O ponto de origem da performatividade é relativamente distante da ciência econômica, mais especificamente na filosofia da linguagem, com John Langshaw Austin. Apesar de morrer aos 48 anos, ele se tornou um dos filósofos mais importantes de Oxford, por elaborar que "as afirmações agora não só dizem sobre o mundo como fazem algo no mundo. Não descrevem a ação, praticam-na" (Ottoni, 2002 p. 130, ênfase no original).

Para ele, usar afirmações somente “para 'descrever' algum estado, ou para 'afirmar algum fato', que deve ser verdadeiro ou falso" (Austin, 1962, p. 1) é cometer aquilo que ele chama de "falácia de constatação" (p. 3) - ou seja, dizer que afirmações seriam apenas constatações neutras sobre o que está sendo observado. Ao dizer "Eu aceito" durante um casamento "eu não estou reportando um casamento: eu estou acedendo a ele" (p. 6). Ou seja, o fato de se concordar que 
haja um casamento faz parte do próprio ato de casamento, dadas as circunstâncias apropriadas (p. 8).

$\mathrm{Na}$ abordagem de Austin, existem condições para que ocorra o ato performativo. Ele chama essas condições de "condições de felicidade", as quais incluem a necessidade de se conformar a procedimentos convencionais com os actantes - cientistas, políticos, professores, instituições, leis, ciência, etc. O procedimento deve ser executado pelos participantes correta e completamente, e supõe-se que os participantes continuem a agir de acordo (p. 14-15). Sem essas condições o "rito performativo" não ocorre e, ao invés disso, a afirmação é apenas uma afirmação "infeliz”, sem influência. No exemplo do casamento, "Eu os declaro marido e mulher" deve cumprir essas condições de felicidade, como a de ser reconhecida pela lei, estar de acordo com a vontade dos participantes, especialmente o noivo, a noiva e o representante da autoridade que valida o casamento, além das testemunhas - e supõe-se que os nubentes continuam a agir de acordo após a realização do ato performativo.

Com isso, ele divide o ato da fala em três atos: locucionário, ilocucionário e perlocucionário, ou performativo (p. 103). Um ato locucionário é simplesmente o ato de falar uma palavra; o ato ilocucionário é o ato ativo, que indica iniciativa; o ato perlocucionário é o que causa um efeito nas outras pessoas às quais a fala se dirige, também chamado de ato performativo. Um exemplo pode ser examinado na seguinte situação: durante um incêndio, uma pessoa grita a palavra "Fogo!" esse seria o ato locucionário; o ato ilocucionário é o ato de se avisar que o local em questão está pegando fogo; o efeito do ato performativo é que as pessoas deixem o local que está pegando fogo (Fernández, 2003, p. 147).

A performatividade foi aplicada a outros campos além da linguística ${ }^{6}$, incluindo a economia ${ }^{7}$. Em economia, a performatividade também borra a linha entre ciência e técnica ${ }^{8}$, e é capaz de trazer o mercado como como local de transações (marketplace) para a análise econômica (Callon, 1998).

\footnotetext{
${ }^{6}$ Aplicar a performatividade austiniana original às ciências sociais não é factível porque se trata de um conceito puramente linguístico, por isso requer modificações (MacKenzie, 2007, p. 56).

${ }^{7}$ Macenzie (2007, p. 66) nos dá um exemplo de uma aplicação econômica: "Um disco de metal ou um pedaço de papel não é moeda apenas por meio de suas propriedades físicas; é moeda porque é crível dizer que é um meio de troca e reserva de valor, e essa crença é validada pelas práticas que informa. Nossa crença compartilhada, de que os pedaços de papel que chamamos de 'cédulas' são dinheiro, leva-nos a tratar esses pedaços de papel de forma que eles se constituem dinheiro."

8 "O conceito de performatividade borra a linha entre "ciência" e "técnica", porque é observado que economistas experimentais produzem tanto conhecimento teórico quanto economistas em Teoria dos Jogos.
} 
$\mathrm{Na}$ economia, a performatividade chama a atenção para a relação entre os objetos de estudo com suas ferramentas. Quando uma teoria é elaborada, ela inicialmente está confinada ao mundo em que o modelo 'fecha', em que os axiomas do modelo permitem que se chegue ao resultado que se propôs. Mas para transpor o mundo acadêmico, o processo depende de vários fatores que estão fora do alcance dos modeladores.

Para passar do mundo da teoria, do mundo dos artigos e gráficos em direção à aplicação no mundo real, no qual há consequências reais, há uma rede de actantes que criam uma complexidade incalculável em inúmeros enunciados e modelos que competem entre si, e passam por várias modificações no processo. Como exemplo, suponhamos que um cientista desenvolva um novo estimador econométrico: ele deriva e aplica os dados para seu modelo, possibilitado pelo novo estimador; e como fazer com que esse modelo seja aceito? Apenas ser acurado e replicar a realidade não é o suficiente para que ele seja aceito, ele precisa ser apresentado em congressos e ser publicado em revistas de alta circulação, para que a partir daí possa ter a chance de sair do ambiente acadêmico e influenciar o mundo.

$\mathrm{O}$ conceito de performatividade foi aplicado à economia pelos sociólogos Michel Callon e Donald MacKenzie; este com seu livro An Engine, Not a Camera $^{9}$ : How Financial Models Shape Markets (2006). Nesse livro, Mackenzie (2006, p. 16) argumenta que "existem alguns casos em que a economia, no sentido estrito e acadêmico 'performa, molda e formata' a economia". Ele distingue três níveis de performatividade na economia:

1) O nível genérico, em que um aspecto da economia é determinado simplesmente por observação, o método descritivo básico; é usado não só na academia, mas também por outros agentes mais próximos à tomada de decisões, como policymakers, reguladores e demais participantes do mercado;

2) O nível efetivo, quando um aspecto da economia não é somente observado, mas também é incorporado ao mercado e também modifica uma parte do mercado após sua incorporação, isto é, “os processos

E ao borrar a linha, a relação entre teoria e prática pode ser entendida melhor, pois toda a linha de produção da academia até a aplicação está envolvida. Uma hoste de profissões, competências e coisas não humanas são necessárias para a economia acadêmica ser bem-sucedida. Cada uma dessas partes 'faz' a economia“" (Callon, 2007, p. 333).

${ }^{9} \mathrm{O}$ título é uma referência seminal trabalho de Milton Friedman sobre metodologia na teoria econômica; a metáfora que ele invoca é que a economia deve ser "um motor para analisar [o mundo], não uma reprodução fotográfica deste" (Friedman, 1953, p. 35). 
econômicos que incorporam o aspecto em questão devem fazer uma diferença em relação aos seus análogos, em que o aspecto em questão esteja ausente" (MacKenzie, 2007, p. 60, ênfase no original);

3) E o nível barnesiano, em que há a possibilidade dos processos ou resultados econômicos serem alterados para corresponderem melhor ao modelo; em outras palavras, a economia como objeto é modificada pela economia como disciplina. Enquanto que performatividade efetiva tem um efeito nos processos econômicos, o efeito da performatividade barnesiana é fazer com que o uso prático da teoria faça com que os processos se tornem mais parecidos com o que a teoria diz (MacKenzie, 2007, p. 59-69).

Seu estudo de caso demonstra que, através de uma pesquisa sobre a história, sociologia e economia do mercado financeiro, os financistas criaram uma cultura única, presente no ambiente das bolsas de valores e nas reuniões executivas (ver também Abolafia, 1998). Apesar disso, modelos financeiros têm sérios problemas para corresponderem à realidade, sendo pouco úteis para praticantes, com exceção do modelo Black-Scholes (Moosa, 2017a, p. 28-31). Uma das conclusões de MacKenzie foi de que o modelo de Black-Scholes-Merton ajudou a legitimar o mercado de derivativos e alterar os padrões de preços, pelo menos nos anos iniciais de sua adoção.

Ele chama a atenção para o fato de que o modelo Black-Scholes começou a ter efeitos imediatos ${ }^{10}$. À medida que o modelo Black-Scholes foi popularizado, começou a haver uma correspondência entre os resultados preditos pelo modelo e os resultados reais do pregão ${ }^{11}$ (MacKenzie, 2006, p. 256). Esse processo foi auxiliado graças à grande difusão do modelo por meios diversos, como as tabelas Black-Scholes, que auxiliavam no cálculo de valores precisos de variáveis como preço e volatilidade antes do advento dos computadores, o que na mente de muitos operadores auxiliaria na busca de ganhos de arbitragem. Além disso, os mercados também se tornaram mais parecidos com que o modelo previa, graças às "melhorias tecnológicas à disseminação de preços e processamento de transações” (p. 258).

\footnotetext{
${ }^{10}$ Da entrevista com Malcolm Gladstein, operador da Donaldson, Lufkin \& Jenrette Securities Corporation e usuário do modelo Black-Scholes, sobre o primeiro dia de pregão: "Eu olhei para os preços das calls e olhei para o modelo e as calls estavam de trinta a quarenta por cento sobrevalorizadas! E eu chamei o Myron [Scholes] em pânico e disse 'Seu modelo é uma piada' e ele disse 'Me dê os preços!' e ele foi, conversou com Merton e voltou. Ele disse [sic] 'O modelo está certo'. Eu corri pelo corredor... e disse 'Me dê mais dinheiro, nós vamos conseguir um grande prêmio aqui!'” (MacKenzie, 2006, p. 158).

${ }^{11}$ Versões preliminares do artigo já circulavam bem antes (MacKenzie, 2007, p. 60; ver também Hauger e Taleb (2011), para outros modelos alternativos ao Black-Scholes).
} 
No auge do modelo, Ariel Rubinstein demonstrou que havia uma convergência estatística forte entre o modelo e a realidade (Rubinstein, 1985) ${ }^{12}$. Legitimando o estudo científico de derivativos, Stephen Ross escreveu no verbete "Finance" do New Palgrave Dictionary of Economics de 1987: "Quando julgada por sua habilidade em explicar dados empíricos, a teoria de precificação de opções é a teoria mais bem sucedida não em Finanças, mas como também em toda a ciência econômica" (Ross, 2008) ${ }^{13}$.

Essa série de eventos possibilitou a MacKenzie elaborar a seguinte hipótese: o modelo Black-Scholes, ao invés de simplesmente descrever o comportamento das pessoas que o utilizavam no mercado financeiro, contribuiu para modificá-lo. O modelo em questão possibilitou não só mais um método para o cálculo do preço de derivativos mas também uma forma de tornar o mercado de derivativos como uma empreitada legítima e científica.

Porém, a crise de 1987 modificou esse cenário. Em 19 de outubro de 1987, dia conhecido como a 'Segunda-feira negra', o índice S\&P 500 caiu 20 por cento, junto a quedas simultâneas em mercados internacionais, cessando a correspondência de Rubinstein de forma definitiva (Kindleberger; Aliber, 2005, p. 99; Carlsson, 2007; Mackenzie, 2007, p. 76). A esse efeito, MacKenzie dá o nome de contraperformatividade, em que o uso prático de um modelo pode fazer com que este se conforme cada vez menos com a teoria ou modelo, ou seja, em que os dados não casem com a realidade e o divórcio fique cada vez mais evidente. Portanto, a contraperformatividade mostra que o efeito performativo de um modelo pode ser revertido, caso tenha sido observado.

A possível performatividade do modelo Black-Scholes pôde ser verificada devido à interação entre o modelo em si e toda a rede de apoio no qual ele se sustentava, como pelas planilhas para facilitar cálculo, a cultura financeira e a formulação de uma teoria econômica das finanças. Tal possibilidade não foi verificada em outros modelos financeiros, como o CAPM e o Modigliani-Miller, pois os dados observados não eram parecidos com os preditos pela teoria ou seu efeito era muito ambíguo.

\footnotetext{
12 De uma entrevista com Rubinstein: "Eu caminhei [até a parte mais ativa da bolsa] e olhei para a tela [de preços de mercado] e vi que tinha preços idênticos à folha [de preços Black-Scholes]. Eu disse a mim mesmo 'a academia triunfou'!" (apud MacKenzie, 2007, p. 62).

13 Apesar de citar a segunda edição, esta parte do verbete é idêntico à da primeira.
} 
Deve ser notado que a tese da performatividade ainda gera debates sobre suas aplicações. A performatividade pode ser confundida com engenharia social (Santos; Rodrigues, 2009); ao invés de influenciar e criar comportamentos, a teoria econômica mainstream serviu para legitimar comportamentos prejudiciais já existentes na estrutura capitalista (Spencer, 2020, p. 30). Existem outras críticas, tanto de natureza econômica quanto sociológica, à performatividade: de que legitima a economia neoclássica como imperialista, é reducionista e não consegue explicar de maneira satisfatória contraperformatividade, definições vagas, e até mesmo o vício do relativismo pós-modernista (Brisset, 2019, p. 92ff). MacKenzie é criticado por trivializar a contribuição de Austin e por não explicar de forma clara a sua adaptação da performatividade linguística (Mäki, 2013).

Apesar das críticas, MacKenzie, Callon e outros demonstraram que a relação entre disciplina e objeto é algo que deve ser estudado mais a fundo, e isso pode representar uma mudança sobre como entendemos o processo de desenvolvimento científico. Ela providencia uma resposta à questão do porquê a fórmula Black-Scholes influenciou a economia financeira, a ponto de haver correspondência quase perfeita do resultado do modelo com a realidade, e do porquê dessa correspondência não ser mais observada. Dissertar se a resposta foi satisfatória já não está no escopo do artigo, mas entre as questões geradas pelo estudo de MacKenzie está "podemos esperar que outros domínios da economia apresentem performatividade?" As próximas seções tentarão avaliar se tal framework pode ser aplicado à econometria.

\section{Canais de influência}

O estudo do porquê a ciência econômica ter a forma atual é um dos fundamentos da história do pensamento econômico como disciplina. Mas o estudo de como a influência e difusão por canais de influência na economia se realiza é também um estudo interdisciplinar (Senn, 2008). A penetração do modelo BlackScholes, por exemplo, deu-se por meio de canais de influência acadêmicoprofissionais, especialmente por ser um produto acadêmico que encontrou seu caminho em aplicações reais.

Entre os principais canais de influência, Dequech (2018, p. 480) enumerou sete: a) ensino acadêmico; b) ensino informal (livros e artigos de divulgação científica, blogs); c) organizações estatais e supranacionais; d) organizações 
privadas; e) mídia; f) cortes de justiça ${ }^{14}$; g) e redes. Todas as subdisciplinas da economia fizeram uso desses canais, incluindo a econometria, para a qual os canais a), c) e g) são analisados.

O canal acadêmico é, essencialmente, o canal primário de propagação, pois é o canal no qual os economistas encontram seus pares mais próximos. Foi importante nos anos de formação da disciplina (Morgan, 1990; Louçã, 2007), sendo que periódicos, como a Econometrica, foram os principais meios de divulgação das teorias nascentes de econometria. Porém, os livros-texto são mais eficazes do que artigos devido ao seu potencial de influenciar estudantes que estão se convertendo de leigos para acadêmicos, e têm uma capacidade de não somente comunicar, mas também transformar ideias e conhecimento (Giraud, 2018). É suficiente dizer que os cursos mais bem avaliados de economia têm econometria em sua grade (Johnson et al., 2012; Marshall; Underwood, 2020).

O canal acadêmico tem uma influência íntima com o canal de redes de relacionamento. Louçã (2007, p. 31) nota que "a Econometric Society nasceu sob o projeto de reunir todas as capacidades disponíveis em teoria econômica". E Ragnar Frisch foi o principal articulador dessa rede, pois:

[Frisch] é considerado como a figura central da econometria na década de 1930. Ele central pelo seu trabalho como o primeiro econometrista teórico, pela sua influência pessoal, e porque ele era o centro de uma grande rede onde economia matemática, econometria, e estatística matemática se encontravam (Aldrich, 2010, p. 125, ênfase adicionada).

Ocorreram inúmeras reuniões, congressos, colaborações e artigos que foram possíveis graças à construção de redes entre vários atores no movimento da econometria. E essas redes procuraram se expandir para o setor público, pois quanto mais conectada for a rede entre modeladores e policymakers, mais firme será o desenvolvimento de modelos práticos (Den Butter; Morgan, 1998, p. 471472).

Muitos econometristas eram também autores da teoria da política econômica, como Jan Tinbergen, tiveram um papel importante no canal de organizações públicas. Tinbergen sempre acreditou que o propósito da pesquisa econômica é: “(a) tentar explicar fenômenos econômicos ou (b) recomendar

\footnotetext{
${ }^{14}$ A contratação de economistas como testemunhas especializadas aumentou nos últimos anos e os impactos variam, mas há um efeito, pois "é um truísmo dizer que dinheiro muda tudo, e economistas não são exceção." (Mandel, 1999, p. 113).
} 
políticas ou estruturas econômicas." (Tinbergen, 1991, p. 33). Seu modelo precursor tinha como objetivo recomendar políticas públicas para combater a depressão (Tinbergen, 1936) ${ }^{15}$.

Seu trabalho no modelo de 1936 chamou a atenção da Liga das Nações, que o comissionou para criar um modelo macroeconométrico mundial (Tinbergen, 1939 , p. 10). Apesar de não ser um modelo com objetivo político, encaixando-se mais no canal acadêmico, ele se tornou um marco que demonstrou que a disciplina da econometria estava sendo reconhecida como importante, aumentando o potencial dos trabalhos aplicados. Após a guerra, ele foi apontado como diretor do Departamento de Planejamento Central holandês (Tinbergen, 1947), estabeleceu os fundamentos de uma teoria da política econômica (Tinbergen, 1952) e escreveu um manual de econometria, popular por seu foco em aplicações em políticas públicas (Tinbergen, 1951) ${ }^{16}$.

Alguns economistas entenderam o que estava por acontecer, entre eles, Keynes. Ele dava valor ao poder de persuasão das ideias econômicas, como demonstrado neste excerto célebre:

As idéias dos economistas e dos filósofos políticos, estejam elas certas ou erradas, têm mais importância do que geralmente se percebe. De fato, o mundo é governado por pouco mais do que isso. Os homens [práticos] que se julgam livres de qualquer influência intelectual são, em geral, escravos de algum economista defunto. Os insensatos, que ocupam posições de autoridade, que ouvem vozes no ar, destilam seus arrebatamentos inspirados em algum escriba acadêmico de certos anos atrás (Keynes, 1996 [1936], p. 349).

Seria ingênuo acreditar que quando Keynes falou sobre 'economistas defuntos', ele não estaria se incluindo entre eles no futuro. Pelo contrário, ele não queria esperar se tornar um economista defunto para fazer 'escravos' das ideias que ele estava propondo. Daí a sua insatisfação com o fato de que a pesquisa econométrica deficiente fosse "a principal atividade e raison d'être da Liga das Nações" (Keynes, 1939, p. 568). Ele lançou dúvidas sobre a aplicabilidade do método econométrico para uma ciência que lida com dados tão pouco lineares como a economia.

\footnotetext{
${ }^{15}$ Ele admite que o modelo não teve influência, devido ao timing de seu trabalho: eventualmente a Holanda abandonou o padrão-ouro três meses depois, o que tornou o modelo obsoleto (Magnus; Morgan, 1987, p. 123).

${ }^{16}$ Podemos ver também que os canais de influência podem entrar em intersecção, como Giraud (2018) observou com livros-textos e o canal político.
} 
Econometristas também acreditavam que os métodos econométricos deveriam se tornar ferramentas primárias na elaboração de políticas públicas. Ragnar Frisch também compartilhava do objetivo de influenciar a política, para auxiliar no combate à depressão e à reestruturação do pós-guerra norueguês ${ }^{17}$. Na sua palestra de recebimento do prêmio Nobel memorial de economia, ele inicia dizendo que o papel da econometria é servir ao planejamento econômico e ao melhoramento da condição humana (Frisch, 1969). E não só isso: para ele, o progresso científico ocorre à medida que a humanidade descobre regularidades, porém poderia chegar a um ponto em que a própria humanidade seria capaz de criá-las: "Poderíamos nós ter criado as leis da natureza, ao invés de descobri-las?"

Qual será o impacto de tal ponto de vista? Será, acredito eu, ajudar-nos a pensar de uma maneira menos convencional. Irá nos ajudar a pensar de uma forma mais avançada, mais relativista e menos pré-concebida. No longo prazo isso pode ser indiretamente vantajoso em todas as ciências, também na economia e na econometria (Frisch, 1969, p. 15, ênfase no original).

A possibilidade de que a humanidade pode criar regularidades, incluindo na economia, foi levantada nas seções anteriores, na dicotomia economistas como 'descritores' e 'inventores' e na performatividade. Porém, o efeito performativo só pode ocorrer caso as condições de felicidade sejam cumpridas e estas dependem de cada situação. Para que modelos econométricos possam ter uma influência performativa, eles não somente precisam se propagar pelos canais de influência. Sua rede de actantes é muito maior que a do modelo Black-Scholes, portanto, precisaria de muito mais recursos epistêmicos para fazer com que o rito performativo seja bem-sucedido. A próxima seção vai ponderar sobre esse caso.

\section{Mudanças da década de $\mathbf{1 9 7 0}$}

A econometria tem uma querela: como ferramenta, ela é apenas um método para economistas avaliarem a realidade econômica; ela só pode dizer algo sobre o mundo, sendo incapaz de influenciá-lo, uma tecnologia de análise que o economista deve usar da melhor forma possível e agir para comunicar corretamente o que ele descobre. Caso o economista não cobice posições de poder, seu papel permanece

\footnotetext{
17 "Ele influenciou o pensamento de uma geração inteira de economistas noruegueses. Muitos deles se tornaram soldados de vanguarda na sua luta para melhorar políticas e o planejamento econômico, e Frisch até certo ponto fez com que alguns deles fossem colocados em posições estratégicas" (Bjerve, 1999, p. $550)$.
} 
como o de cientista imparcial, que deve entregar os resultados de seu modelo, fornecer informações e previsões necessárias para políticas frutíferas.

Modelos econométricos se tornaram importantes como técnicas para auxiliar a reconstrução dos países da Europa Central no pós-guerra (e.g. Tinbergen, 1947). Deve existir uma interação constante entre aqueles que formulam modelos e os que formulam políticas, e quanto mais forte for a interação, melhor é a capacidade de criar modelos melhores, pois teoria e prática se unem (Den Butter; Morgan, 1998, p. 455). É possível ilustrar as interações com o caso da Holanda, terra natal de Tinbergen, e um país que tem uma "cultura de modelos" (Van den Bogard, 1999), em que o foco de modelos macroeconômicos com aplicações políticas se tornou proeminente (Plasmeijer; Schoorl, 2000):

\begin{abstract}
Nós nos concentramos no caso holandês aqui [...] porque em nenhum outro país o nível de agência da modelagem e os modelos têm uma análise tão importante, aberta e colaborativa na análise de política econômica. As interações entre modeladores e policymakers começam logo de início: existem amplas discussões entre os peritos econômicos dos partidos e os oficiais do Departamento de Planejamento Central quando o Departamento faz um pronunciamento sobre os efeitos das medidas econômicas propostas nos programas de cada partido político. Essas discussões podem até levar a mudanças na formulação da versão final dos programas dos partidos (Den Butter; Morgan, 1998, p. 456).
\end{abstract}

Após os modelos macroeconométricos de Tinbergen, a Comissão Cowles intentava criar uma nova versão do modelo de 1939 e isso culminou no modelo de Lawrence Klein. Este levou três anos para ser construído e, posteriormente, três anos para ser publicado. No prefácio, ele escreve: "Se nós alcançássemos o objetivo de descobrir padrões de comportamento autônomo, devemos esperar que eles aconteçam sob uma variedade de circunstâncias" (Klein, 1947, p. vii), subentendendo-se possibilidades para um melhor planejamento econômico.

Deve se considerar também que o objetivo de Klein era não só dar evidência negativa, como Tinbergen queria fazer, mas também "descobrir a melhor ou as melhores teorias possíveis" para explicar o ciclo econômico (p. 1). O resultado foram três modelos pequenos da economia americana (o Modelo III tinha 12 equações), e estes deram origens a modelos maiores. À medida que mais variáveis foram introduzidas, as iterações do modelo foram crescendo. Um dos principais 
foi o Modelo Trimestral de Brookings ${ }^{18}$ de mais 200 equações, chegando a mais de 400 equações em seu ápice (Welfe, 2013, p. 20).

Supermodelos como o Brookings eram uma tendência da época ${ }^{19}$. Eles tinham que ser grandes não só para atender ao máximo de setores possíveis, mas também para cobrir todas as variáveis possíveis para simulações de política e previsões, com o intuito de torná-las mais precisas possíveis para aqueles que utilizam os modelos (pois uma boa parte eram modelos comissionados, eles tinham que estar nas expectativas dos seus clientes). As previsões dos macromodelos podem ser comparadas com previsões de tempo e previsões de uso de água - na primeira, o efeito será preparar as pessoas (como levar guarda-chuvas para o passeio), enquanto que no segundo será fazer com que as pessoas ajustem seu comportamento no consumo de água (como diminuição do consumo em uma seca). Na primeira, os agentes não podem fazer nada a respeito do tempo, enquanto que na segunda, eles podem causar um impacto nos níveis de água.

Macromodelos keynesianos assumiram implicitamente que suas previsões eram como previsões do tempo: todos os agentes (com a exceção notável do governo) poderiam tratar as previsões como independentes de seu comportamento (Hoover, 1992, p. 88).

Essas previsões foram sujeitas a inúmeras críticas. A macroeconomia keynesiana teve sua Segunda-feira Negra, que durou metade de uma década. Entre os fatores estão a quebra da curva de Philips, a crítica de Lucas (Lucas, 1976), a proposta de ineficiência da política econômica (Sargent; Wallace, 1976) e a inconsistência dinâmica (Kydland; Prescott, 1977) ${ }^{20}$ - todos estes argumentam de pontos de vista diferentes, mas compartilhando do framework de expectativas racionais, que os agentes econômicos não podem ser racionalmente manipulados pelo governo; pelo contrário, eles vão reagir a anúncios de política de forma previsível e vão anular o efeito que os anúncios deveriam ter.

Do ponto de vista prático, economistas viram seus grandes projetos de desenvolvimento serem reduzidos a resultados abaixo do esperado e até fracassos

\footnotetext{
${ }^{18}$ Em referência à Brookings Institution.

19 Ver Welfe (2013), capítulo 3. Outros notáveis eram o FED-MIT-PENN, o Wharton, o St. Louis e o Hickman-Coe.

20 "Os modelos macroeconométricos de curva de Phillips keynesiana que entraram em colapso na década de 1970 foram, juntamente com seu método de pesquisa associado, transformados em órfãos três vezes: repudiados por Keynes, abandonados pela maior parte da Comissão Cowles, e contrários ao espírito e detalhes do trabalho de Phillips" (Leeson, 1998, p. 79).
} 
(Hirschman, 1969). Os supermodelos ainda não capturavam todas as variáveis possíveis, apesar de seu tamanho. Em consequência, Charles Goodhart enunciou a lei de Goodhart: qualquer regularidade estatística observada tenderá a entrar em colapso quando pressionada por propósitos de controle e política (Goodhart, 2006, p. 758) $)^{21}$. Leeson afirma que a "onda de entusiasmo" com os supermodelos e a curva de Phillips original foi o que mais causou problemas ao prestígio e credibilidade da ciência econômica (Leeson, 1998, p. 78).

O espaço não nos permite abordar esse período de forma aprofundada, mas ficou claro que os modelos eram vistos como ferramentas do desenvolvimento e não conseguiram alcançar o resultado desejado. Pelo contrário, as tentativas de "domar" as variáveis econômicas, de descobrir as manivelas do crescimento econômico, não se concretizaram. Hayek chamou isso de "pretensão do conhecimento" e considerou como a causa dos erros político-econômicos que levara à crise da época (Hayek, 1974) ${ }^{22}$.

No fim, pode se argumentar que eles se tornaram contraperformativos. Os modelos deixaram de dizer algo sobre o mundo, mas ficou claro que não havia como os agentes se comportarem de acordo com o que o modelo prescrevia e as condições de felicidade não poderiam ser cumpridas. Ao contrário da possibilidade de efeitos performativos, Lucas reconheceu que o agente do modelo é uma construção imaginária, e essa ficcionalidade do agente é o que permite o teste de modelos e conclusões de política (De Vroey, 2011, p. 3-4) ${ }^{23}$.

Expectativas racionais se tornaram a crítica mais importante aos poderes dos economistas, por ter conseguido modificar o pensamento macroeconômico de forma radical (Hoover, 1992). E, assim como o keynesianismo do pós-guerra está associado a uma era de crescimento que parecia não terminar, as expectativas racionais estão associadas ao período da Grande Moderação, na qual os ciclos

\footnotetext{
${ }^{21}$ A lei foi enunciada pelo próprio Goodhart durante uma série de conferências patrocinadas pelo Banco Central da Austrália em 1974, de forma meio irônica e meio séria. "O contexto era o seguinte: quando alvos monetários foram introduzidos na década de 1970, vários países escolheram alvos monetários diferentes como o foco principal. Para qualquer agregado que fosse escolhido assim, sua relação subsequente com a inflação e renda nominal tendia ser tornar instável imprevisível (principalmente para os outros agregados além do escolhido)" (Goodhart, 2006, nota 1).

${ }^{22}$ Hayek também entendia o poder das opiniões, distinguindo-as em constitutivas e especulativas, em que as opiniões constitutivas são uma das origens dos fenômenos sociais, enquanto que especulativas são formadas para explicar a causa dos fenômenos sociais (Caldwell, 2003, p. 245). Mais uma vez aparece a dicotomia de Faulhaber-Baumol, entre economistas como inovadores e como descritores.

${ }^{23}$ A função de auxílio à pesquisa foi considerada importante por Lucas: "modelos macroeconométricos da velha guarda eram dignos de elogio porque eles resultavam em conclusões de política, uma virtude que, ele acha, perdeu-se nos modelos novos-keynesianos" (De Vroey, 2011, p. 4).
} 
econômicos ficaram menos voláteis e a economia estável (Stock; Watson, 2002), o que levou Lucas a proclamar que o problema do ciclo econômico "foi resolvido" (Lucas, 2003).

Porém, o keynesianismo não foi extinto. Pelo contrário, ele se reorganizou e partiu para o "contra-ataque", reinventando-se em novas formas, como o "novo keynesianismo" (Goutsmedt et al, 2019). Não somente isso, mas também modelos macroeconométricos nunca foram completamente aposentados dos bancos centrais - apenas foram adaptados e diminuíram sua escala - e são utilizados em conjunto com modelos DSGE (Tovar, 2009). E a crise de 2007-2008 levou a uma nova discussão sobre o poder de influência dos modelos e do seu possível papel na difusão dos efeitos da crise (Commitee on Science and Technology, 2010).

No fim, existe um componente humano nesses embates. Lucas admitiu que

Uma consequência puramente sociológica do advento das expectativas racionais foi uma inversão dessa mesa retórica: agora keynesianos estão na defensiva sobre seus modelos (ou falta destes). Não há dúvida que essa vantagem vai se revelar transiente. Os keynesianos já estão aprendendo a 'improvisar' em questões de política, sem o uso do aparato IS-LM, ou sem nenhum destes (carta de Lucas a Robert Barro, não datada apud De Vroey, 2011, p. 16-17).

Nota-se que é, novamente, um problema da relação entre o objeto e a disciplina, economistas e economia. C. S. Lewis avalia que o abandono do modelo ptolemaico não foi possível apenas pelo influxo de novos dados, mas também que "quando as alterações na mente humana produzem uma antipatia suficiente contra o velho modelo e um desejo ardente pelo novo, os fenômenos para dar suporte ao novo aparecerão de forma obediente" (Lewis, 2015 [1964], p. 209). De Vroey faz uma crítica à afirmação anterior de Lucas, porque não são apenas os fatores sociológicos que estão em xeque: “eles podem ter agido com base na ideologia, mas no fim o resultado foi que novos modelos foram criados! O que é verdadeiro para keynesianos é também para anti-keynesianos" (De Vroey, 2011, p. 17). Portanto, os fenômenos para dar "suporte ao novo apareceram de forma obediente" tanto para keynesianos quanto para seus sucessores e adversários ${ }^{24}$.

\footnotetext{
${ }^{24}$ Lewis (2015 [1964]) afirma que um dos postulados mais fundamentais do modelo ptolomaico era de que a esfera celeste era perfeita e ordenada, diferente do mundo caótico e pecaminoso em que vivemos. Apesar dos novos dados serem o fator mais importante na mudança, um filósofo medieval ficaria mais chocado com a descoberta de que a esfera celeste é tão caótica e destrutiva quanto a terrestre, cheia de buracos negros e supernovas e sem vida, do que com a física newtoniana. Talvez a observação de um evento parecido na economia possa causar um choque similar. A Grande Depressão e a crise da década de 1970
} 


\section{Conclusão: transitoriedade dos modelos}

A tese de MacKenzie é um estudo de caso: o modelo Black-Scholes fez com que houvesse uma mudança no padrão dos agentes no qual se conformava com o modelo, "um 'motor'... uma força ativa que transforma seu ambiente, não uma câmera, recordando-o passivamente" (MacKenzie, 2006, p. 12). Assim, este artigo gerou pensamentos gerais em propor guidelines para futuros estudos de casos sobre a performatividade da economia e suas subdisciplinas, como a econometria.

A performatividade suscitou debates na academia e sua aceitação não é unânime. Pesquisas futuras devem seguir a recomendação de Frey (2006) e se focar em estudos de caso, como o modelo Black-Scholes, ao invés de influência de disciplinas inteiras, como a econometria. Existem casos de modelos econométricos individuais que tiveram um efeito performativo barnesiano? Potencialmente sim, mas a disciplina da econometria tem demonstrado inúmeros problemas com aplicações no mundo real (Leamer, 1983; Moosa, 2017b), tornando seus efeitos claramente contraperformativos, como foi na década de 1970, incapaz de cumprir as condições de felicidade.

Porém, como Callon (2007, p. 327) afirmou, "performatividade não é sobre criar, mas fazer acontecer". A performatividade não pode criar nada ex nihilo, mas faz com que as expressões de um evento se tornem tão parte do fenômeno quanto o evento em si, incluindo a mudança de comportamento dos agentes para se conformarem ao modelo. Parafraseando Karl Polanyi ${ }^{25}$, "o modelo foi planejado, os efeitos performativos que fazem com que os agentes passem a agir de forma semelhante ao modelo não" ${ }^{26}$.

Devemos fazer um esforço em entender efeitos não intencionais das ações econômicas e como elas se difundem através dos canais de influência, mesmo que

podem ser considerados eventos assim, mas, mesmo que eles tenham perturbado o pensamento ortodoxo de sua época, posteriormente escolas de pensamento rivais promoveram diferentes explicações da forma que Lucas argumentou na citação acima. Por outro lado, a economia, juntamente com as outras ciências sociais, tem um problema de que o poder de teste dela é baixo, e isso gera oportunidade para falsos paradigmas persistirem (Akerlof; Michaillat, 2018).

25 “O laissez-faire foi planejado; o planejamento não" (Polanyi, 2001 [1944], p. 147).

26 Porém, a possibilidade de pessoas em posição de poder estudarem esses efeitos e tentarem criar artificialmente as condições de felicidade pode explicar a crítica de que a performatividade seja uma forma de engenharia social. A situação é semelhante à lei de Goodhart, em que a exploração de uma regularidade pode fazer com que esta desapareça. Será que a exploração de condições de felicidade pode fazer com que o efeito performativo desapareça? O estudo da teoria de arquitetura de escolha (nudge) parece ser um campo promissor a tais estudos. 
isso signifique uma reavaliação do papel do economista e das instituições econômicas em uma direção mais longe do que Stigler imaginava. Em maio de 2020, a justiça alemã determinou que o Banco Central Europeu foi além das atribuições de políticas monetárias neutras ao interferir na política econômica, uma decisão que pode ter consequências sérias e indica uma influência econômica maior das entidades econômicas do que se supõe (Tooze, 2020).

A performatividade auxilia nesse entendimento não somente quando há um processo bem-sucedido, mas também quando o processo falha. Mais do que isso, um modelo previamente performativo pode simplesmente parar de ter esse efeito, como foi o modelo Black-Scholes. Portanto, a performatividade também chama a atenção para o fato de que a ciência está sempre evoluindo, descartando ou absorvendo modelos que uma vez dominaram a paisagem científica - mesmo que o modelo anterior estivesse incorreto ou equivocado, ele ainda exerceu uma influência e seus defensores acreditavam que era uma representação correta da realidade.

\section{Referências}

ABOLAFIA, M. Markets as cultures: an ethnographic approach. Sociological Review, v. 46, n. 1, p. 69-85, 1998.

ACOCCELlA, N.; DI BARTOLOMEO, G.; HUGHES HALLETT, A. Macroeconomic paradigms and economic policy: from the Great Depression to the Great Recession. Cambridge: Cambridge University Press, 2016.

AKERLOF, G.; MICHAILLAT, P. Persistence of false paradigms in low-power sciences. Proceedings of the National Academy of Sciences, v. 115, n. 52, p. 13228-13233, 2018.

ALDRICH, J. The econometricians' statisticians, 1895-1945. History of Political Economy, v. 42, n. 1, p. 111-154, 2010.

ARIDA, P. A história do pensamento econômico como teoria e retórica (1984). In: GALA, P.; REGO, J. (Orgs.). A história do pensamento econômico como teoria e retórica. São Paulo: Editora 34, 2003, p. 13-44.

AUSTIN, J. How to do things with words. Oxford: Clarendon Press, 1962.

BLINDER, A. Economics becomes a science - or does it? (1999). In: CROW, R. (Ed.). The best of Business Economics. Londres: Palgrave Macmillian, 2015, p. 255-270. 
BJERVE, P. The influence of Ragnar Frisch on macroeconomic planning and policy. In: STRØM, S. (Org.). Econometrics and economic theory in the $20^{\text {th }}$ century. Cambridge: Cambridge University Press, 1999, p. 531-559.

BOLDYREV, I.; SVETLOVA, E. (Eds.). Enacting dismal science: new perspectives on the performativity of economics. Londres: Palgrave Macmillian, 2016.

BRISSET, N. Economics and performativity: exploring limits, theories and cases. Londres: Routledge, 2019.

CALDWELL, B. Hayek's challenge: an intellectual biography of F. A. Hayek. Chicago: The University of Chicago Press, 2003.

CALLON, M. Introduction: The embeddedness of economic markets in economics. In: CALLON, M. (Org.). The laws of the markets. Oxford: Blackwell, 1998.

CALLON, M. What does it mean to say that economics is performative? In: MACKENZIE, D.; MUNIESA, F.; SIU, L. (Eds.). Do economists make markets? On the performativity of economics. Princeton: Princeton University Press, 2007, p. 311-357.

CARLSON, M. A brief history of the 1987 stock market crash with a discussion of the Federal Reserve response. Working Paper 2007-13. Washington: Federal Reserve Board, 2007.

CAVANAUGH, J. Performativity. Oxford Bibliographies. Disponível em: 10.1093/obo/9780199766567-0114. Acesso: 19 abr. 2020.

COMMITTEE ON SCIENCE AND TECHNOLOGY. Building a science of world economics for the real world. Committee on Science and Technology - House of Representatives - One Hundred Eleventh Congress, Second Session, July, $20^{\text {th }}$, 2010 Serial No. 111-1006, 2010.

DEN BUTTER, F.; MORGAN, M. What makes the models-policy interaction successful? Economic Modelling, v. 15, p. 443-475, 1998.

DEQUECH, D. Institutions in the economy and some institutions of mainstream economics: from the late 1970s to the 2008 financial and economic crisis. Journal of Post-Keynesian Economics, v. 41, n. 3, p. 478-506, 2018.

DE VROEY, M. Lucas on the relationship between theory and ideology. Economics: The Open-Access, Open-Assessment Journal, v. 5, p. 1-39, 2011. 
DE VROEY, M. A history of macroeconomics from Keynes to Lucas and beyond. Cambridge: Cambridge University Press, 2016.

DUPRÉ, J. Fact and value. In: KINCAID, H.; DUPRÉ, J.; WYLIE, A. (Eds.). Value-free science? Ideals and illusions. Oxford: Oxford University Press, 2007, p. 27-41.

FAULHABER, G. R.; BAUMOL, W. J. Economists as innovators: practical products of theoretical research. Journal of Economic Literature, v. 26, n. 2, p. 577-600, 1988.

FERNÁNDEZ, R. McCloskey, Mäki e a verdade. In: GALA, P.; REGO, J. A história do pensamento econômico como teoria e retórica. São Paulo: Editora 34, 2003, p. 119-150.

FREY, B. How influential is economics? De Economist, v. 154, p. 295-311, 2006.

FRIEDMAN, M. The methodology of positive economics. In: FRIEDMAN, M. Essays in positive economics. Chicago: University of Chicago Press, 1966, p. 343.

FRISCH, R. From utopian theory to practical applications: the case of econometrics. 1969. Nobelprize.org. Disponível em: http://www.nobelprize.org/ uploads/2018/06/frisch-lecture-1.pdf.

GARCIA-PARPET, M. A construção social de um mercado perfeito: o caso de Fontaines-en-sologne. Estudos Sociedade e Agricultura, v. 11, n. 1, p. 5-44, 2003 [1986].

GIRAUD, Y. Textbooks in the historiography of economics. In: DÜPPE, T.; WEINTRAUB, E. R. (Eds.). A contemporary historiography of economics. London: Routledge, 2018, p. 137-154.

GOODHART, C. A. The ECB and the conduct of monetary policy: Goodhart's law and lessons from the Euro area. Journal of Common Market Studies, v. 44, n. 4, p. 757-778, 2006.

GOUTSMEDT, A.; PINZÓN-FUCHS, E.; RENAULT, M.; SERGI, F. Reacting to the Lucas's critique: the Keynesian's reply. History of Political Economy, v. 51, n. 3, p. 535-556, 2019.

HAYEK, F. The pretence of knowledge. 1974. Disponível em: http://www.nobelprize.org/nobel_prizes/economic-sciences/laureates/1974/hayeklecture.html. 
HAUGER, E.; TALEB, N. Option traders use (very) sophisticated heuristics, never the Black-Scholes-Merton formula. Journal of Economic Behavior \& Organization, v. 77, n. 2, p. 97-106, 2011.

HIRSCHMAN, A. Projetos de desenvolvimento. Rio de Janeiro: Zahar, 1969.

HOOVER, K. The rational expectations revolution: an assessment. Cato Journal, v. 12, n. 1, p. 81-96, 1992.

JOHNSON, B.; PERRY, J.; PETKUS, M. The status of econometrics in the economics major: a survey. Journal of Economic Education, v. 43, n. 3, p. 315-324, 2012.

KEYNES, J. M. A teoria geral do juro do emprego e da moeda. São Paulo: Nova Cultural, 1996 [1936]. (Série Os Economistas).

KEYNES, J. M. Professor Tinbergen's method. The Economic Journal, v. 49, p. 558$568,1939$.

KLEIN, L. Economic fluctuations in the United States 1921-1941. New York: John Wiley \& Sons, 1947.

KINDLEBERGER, C.; ALIBER, R. Manias, panics and crashes: a history of financial crises. Nova Jersey: John Wiley, 2005.

KOGUT, B.; MACPHERSON, J. The mobility of economists and the diffusion of policy ideas: the influence of economics on national policies. Research Policy, v. 40, n. 10, p. 1307-1320, 2011.

KUHN, T. S. The structure of scientific revolutions. Chicago: University of Chicago Press, 1970 [1962].

KYDLAND, F.; PRESCOTT, E. Rules rather than discretion: the inconsistency of optimal plans. Journal of Political Economy, v. 85, n. 3, p. 473-492, 1977.

LEAMER, E. Let's take the con out of econometrics. American Economic Review, v. 73, n. 1, p. 31-43, 1983.

LEESON, R. 'The ghosts I called I can't get rid of now': the Keynes-TinbergenFriedman-Phillips critique of Keynesian macroeconometrics. History of Political Economy, v. 30, n. 1, p. 51-94, 1998.

LEWIS, C. S. A imagem descartada: para compreender a visão medieval do mundo. São Paulo: É Realizações, 2015 [1964]. 
LOUÇÃ, F. The years of high econometrics: a short history of the generation that reinvented economics. Londres: Routledge, 2007.

LUCAS, R. Econometric policy evaluation: a critique. In: BRUNNER, K.; MELTZER, A. The Phillips curve and labor markets. Nova Iorque: Elsevier, 1976, p. 19-46.

LUCAS, R. Macroeconomic priorities. American Economic Review, v. 93, n. 2, p. 1-14, 2003.

MACKENZIE, D. An engine, not a camera: how financial models shape markets. Cambridge: MIT Press, 2006.

MACKENZIE, D. Is economics performative? Option theory and the construction of derivative markets. In: MACKENZIE, D; MUNIESA, F.; SIU, L. (Eds.). Do economists make markets? On the performativity of economics. Princeton: Princeton University Press, 2007, p. 54-87.

MAGNUS, J.; MORGAN, M. The ET interview: Professor J. Tinbergen. Econometric Theory, v. 3, p. 117-142, 1987.

MÄKI, U. Performativity: saving Austin from MacKenzie. In: KARAKOSTAS, V.; DIEKS, D. (Eds.). EPSA11 Perspectives and Foundational Problems in the Philosophy of Science. Berlim: Springer, 2013, p. 443-453.

MANDEL, M. Going for the gold: economists as expert witnesses. Journal of Economic Perspectives, v. 13, n. 2, p. 113-120, 1999.

MARSHALL, E.; UNDERWOOD, A. Is economics STEM? Trends in the discipline from 1997 to 2018. Journal of Economic Education, v. 51, n. 2, p. 167-174, 2020.

MOOSA, I. Publish or perish: perceived benefits versus unintended consequences. Cheltenham: Edward Elgar, 2017a.

MOOSA, I. Econometrics as a con art: exposing the limitations and abuses of econometrics. Cheltenham: Edward Elgar, 2017b.

MORGAN, M. The history of econometric ideas. Cambridge: Cambridge University Press, 1990.

NELSON, R. The economics profession and the making of public policy. Journal of Economic Literature, v. 25, n. 1, p. 49-91, 1987. 
PINTO, H. The role of econometrics in economic science: an essay about the monopolization of economic methodology by econometric methods. Journal of Socio-Economics, v. 40, p. 436-443, 2011.

PLASMEIJER, H.; SCHOORL, E. The neo-classical synthesis in the Netherlands: a demand and supply analysis. In: PSALIDOPOULOS, M. (Ed.). The canon in the history of economics. Londres: Routledge, 2000, p. 220-243.

POLANYI, K. The great transformation: the political and economic origins of our time. Boston: Beacon Press, 2001 [1944].

ROSS, S. Finance. In: DURLAUF, S. N.; BLUME, L. E. The New Palgrave: dictionary of economics. Londres: Palgrave Macmillian, 2008.

RUBINSTEIN, M. Nonparametric tests of alternative option pricing models using all reported trades and quotes on the 30 most active CBOE option classes from August 23, 1976 through August 31, 1978. Journal of Finance, v. 40, n. 2, p. $455-480,1985$.

SANTOS, A.; RODRIGUES, J. Economics as social engineering? Questioning the performativity thesis. Cambridge Journal of Economics, v. 33, p. 985-1000, 2009.

SARGENT, T.; WALLACE, N. 'Rational expectations,' the optimal monetary instrument, and the optimal money. Journal of Political Economy, v. 83, n. 2, p. 241-254, 1976.

SENN P. The theory and measurement of influence in the history of economic thought. In: BACKHAUS, J. G. (Ed.). Political economy, linguistics and culture. Berlin: Springer, 2008, p. 15-43.

SPENCER, D. Economics and 'bad' management: the limits to performativity. Cambridge Journal of Economics, v. 44, n. 1, p. 17-32, 2020.

STIGLER, G. The process and progress of economics. Nobel Memorial Lecture, 8 December, 1982. Nobelprize.org. Disponível em: https://www.nobelprize.org/ uploads/2018/06/stigler-lecture.pdf. Acesso: 12 Mai. 2020.

STOCK, J.; WATSON, M. Has the business cycle changed and why? NBER Macroeconomics Annual, v. 17, p. 159-218, 2002.

TINBERGEN, J. An economic policy for 1936 (1936). In: KLAASEN, L. et al. Jan Tinbergen: selected papers. Amsterdã: North Holland, 1959, p. 36-84.

TINBERGEN, J. Statistical testing of business-cycle theories: a method and its application to investment activity. Genebra: League of Nations, 1939. 
TINBERGEN, J. Central planning in the Netherlands. The Review of Economic Studies, v. 15, n. 2, p. 70-77, 1947.

TINBERGEN, J. Econometrics. New York: Blakiston, 1951.

TINBERGEN, J. On the theory of economic policy. Amsterdam: North Holland, 1952.

TINBERGEN, J. The functioning of economic research. Journal of Economic Issues, v. 25, n. 1, p. 33-38, 1991.

TOOZE, A. The death of the Central Bank myth. Foreign Policy, May 13, 2020. Disponível em: https://foreignpolicy.com/2020/05/13/european-central-bankmyth-monetary-policy-german-court-ruling/. Acesso: 14 Mai. 2020.

TOVAR, C. DSGE and Central Banks. Economics: The Open-Access, OpenAssessment Journal, v. 3, p. 1-31, 2009.

VAN DEN BOGAARD, A. The cultural origins of the Dutch modelling practice. Science in Context, v. 12, n. 2, p. 333-350, 1999.

WELFE, W. Macroeconometric models. Heidelberg: Springer, 2013.

\section{Agradecimentos}

Gostaria de agradecer à CAPES pelo apoio financeiro durante o mestrado, quando iniciei a pesquisa desse artigo e a meu orientador, Geraldo Edmundo Silva Junior. Gostaria também de agradecer aos pareceristas e editores da revista. 